\title{
Shaanxi Province low-carbon economic construction of the indicator system and evaluation
}

\author{
Yang Qing ${ }^{1, a}$, Zhang Caicai ${ }^{2, b}$, Li Feng ${ }^{3, c}$ \\ ${ }^{1}$ School of Management, Northwestern Polytechnical University, Xi'an 710072, China \\ ${ }^{2}$ School of Management, Northwestern Polytechnical University, Xi'an 710072, China \\ ${ }^{3}$ School of Management, Northwestern Polytechnical University, Xi'an 710072, China \\ aYtsing212@nwpu.cn, b979643553@qq.com, c393573131@qq.com
}

Keywords: low-carbon economy; evaluation indicator system; factor analysis; Shaanxi province

\begin{abstract}
Low-carbon economy is under the guidance of the concept of sustainable development, with the foundation of low energy consumption, low pollution and low emission, through technological innovation, system innovation, industrial restructuring, new energy development and other means, to achieve a win-win economic development and ecological protection, the new economic development patterns. This paper with the foundation of the elaboration the low-carbon economic connotation and the composition elements, selected the evaluation of a low-carbon economy development level evaluation system to build a low-carbon economy, creates a low-carbon economic development level of the factor analysis model and has a comprehensive evaluation of low-carbon economy development level of Shaanxi Province in recent years, and the empirical research for low-carbon economy development level.
\end{abstract}

\section{Introduction}

With the continuous development of economic globalization, the energy shortages and global warming issues caused by the human life and the production activities have gone up to a serious worldwide challenge in the contemporary society. In 2003, the UK government first proposed "Low-carbon economy" in their Energy White Paper named "Our energy future: creating a low-carbon economy", which has aroused extensive concern in the international communities. Therefore, "Low-carbon economy" based on low energy consumption, low pollution, low emission, becomes a new tide of world revolution. Not merely almost every national governments launched a series of actions about low- carbon economy, also, the domestic scholars as well as the foreigners carried on the multi-angle research from various field of low-carbon economy. In fact, the focus of these studies mainly centralized on the importance and the paths of the development of the low-carbon economy, the economic growth and carbon emission, the policies and the ways of reduction of carbon emissions, etc. however, there is no explicit definition for low-carbon economy, especially, there is less research for the building the system of low-carbon economy indicator system.

At present, the domestic scholars' researches for the low-carbon economy construction of indicator system mainly concluding: Professor Jiafeng $\mathrm{Fu}$, from China Environmental Science Research Institute, and other professors propose some low-carbon indicators of the economic development system which comprise: low-carbon consumption indicators, low-carbon resource indicators, cultural development indicators and low-carbon policy indicators [1]. Represented by Professor Dali Hu, some professors proceeding from the perspective of the connotations of low-carbon economy and the path of industrial chain, then put forward to build the logical framework of a low-carbon economic evaluation and the proposed indicator system of low-carbon economy evaluation [2]. Professor Ma Jun and others t from the view of low-carbon city, construct the evaluation indicator system including indicators of economic development, industrial development indicators, the development of science and technology indicators, indicators of the social support and the environmental support [3]. Professor Changyi Ye with others deem that the 
level of the development of low-carbon economy is mainly decided by the potential of developing low-carbon from three aspects of economic development, namely economic development, the level of technology, resource endowments, furthermore, constructing the indicator system for the development of low-carbon economy[4].And some just study an area of low-carbon economy indicator system, for instance, Liu Yong, Xu Zheng, Li Yue, they investigate the county in Hebei Province and provide the low-carbon evaluation indicator system via the establishment of social indicators, economic indicators, environmental indicators and technical indicators[5]; Professor Bimei Feng classifies the evaluation indicator system into the overall layer, system layer, state layer, variable layer and feature layer based on the development of low-carbon economy information in Hubei province, then conducts the empirical studies on that[6]. Professor Yanfeng Sun starts from the actual situation of Xiamen to build the tree structure of the index system, which is divided into target layer, control layer and indicators layer, further, he builds a low-carbon economy evaluation index system for Xiamen city [7].

The above research results mirror the research trend of China's low-carbon economy evaluation index system. Yet, aiming at low-carbon economic development in Shaanxi Province, the evaluation index system still exists the following issues to be addressed: First, some indicators referred above do not conform to the characteristics of the development of low-carbon economy in Shaanxi Province; second, there is no explicit analysis to the logical relationship among some selected indicators. Based on the above problem, in this paper authors build the indicator system in line with the characteristics of low-carbon economic development in Shaanxi Province based on the analysis of the connotation of a low-carbon economy and then evaluate the level of development of low-carbon economy in Shaanxi Province.

\section{The Connection of Low-Carbon Economy}

In recent years, scholars have done a lot of researches about low-carbon economy, since the difference among the field of study, the starting point and the methods, at present, there is no standard concept about low-carbon economy in academic community, but they pervasively agree that: low-carbon economy is the model based on low energy consumption, low pollution, low emission, which should go through the technological innovation, improving energy efficiency, reduce emissions, in response to global climate change and environmental energy problems.

From above analysis, it is clear known that the essence of low-carbon economy is energy efficiency and clean energy structure, and the core is the energy technology innovation and the system innovation, aiming to slow down the speed of climate change and promote the sustainable development of human beings. Therefore, a low-carbon economy is the model of economic development which depends on science \& technology innovation and policy measures, aiming to reduce greenhouse gas emissions. The core products of the low-carbon economy comprise of low-carbon technology and low-carbon energy development \& utilization, and its foundation includes the establishment of the low-carbon energy system, the low-carbon technology system and the low-carbon industry structure; the establishment of the production model and the consumption patterns which adapt to the development of low-carbon and the various policy measures, the law system and the market mechanism which are highly encouraged to develop, finally reaching to the energy efficient utilization and clean energy structure.

\section{Low-Carbon Economy Evaluation Indicator System Construction}

In order to effectively measure the level of low-carbon economic development, the scientific evaluation indicator system should be designed to synthetically measure the level of low-carbon economic development, for improve the factors which restrict regional low-carbon development.

\section{A. The Principle of Construction of the Indicator System}

1) Scientific Principle. Indicator system construction must have some degree of theoretical basis, which can be able to accurately and objectively reflect the connotation of low-carbon economy. 
2) The System Principle. All aspects of the factors affected low-carbon economy development should be taken into account when indicator system designed; avoiding one-sidedness resulted by single factor, striving to the explicit hierarchy and rigorous systematicness.

3) The Feasibility Principle. The purpose of the construction of the indicator system is mainly to evaluate the condition of low-carbon economic development, so the feasibility is needed, especially the convenience of data collection, with respect to whose uneasily collected data indicators should not be contained into the system.

4) The Principle of Independence. The process of choosing evaluation indicators should have independence respectively, avoiding to select repetitive indicators, decreasing the correlation of indicators, to ensure the index system is scientific and objectivity of evaluation results.

5) The Dynamic Principle. Indicator system should be guaranteed with relative stability, at the same time, they should also has some degree of dynamics, the weight of indicators could change along with the change of low-carbon economic development level ,generating more reliable operability.

6) The Simplicity Principle. Indicator system should be as simple and specific as possible, which is convenient for the public to concern, understand and apply, also for relative government department to draft relative policies

\section{B. The Selection and the Description of Evaluation Indicator System}

At present, the low-carbon economy has become a hot issue universally concerned by international communities. However, with respect with comprehensive evaluation researches about low-carbon economy development level is relatively less, especially lacking the quantitative and the qualitative analysis from the angle of combining analysis and judgment. This indicator system constructs the low-carbon economy level 3 evaluation indicator system including: target layer, criterion layer and indicator layer, which is based on domestic and foreign scholars' study researches on low-carbon economic development level research and combined with the actual situation of Shaanxi province, The first layer is target layer which stands for low-carbon economic development level. The criteria layer is constituted by two of the indicators, namely, low-carbon technical indicators, the social environment. The third layer is in the above two aspects established under some specific evaluation indicators, and ultimately constitutes the low-carbon economy evaluation indicator system. By drawing on the researches and related experts' studies, authors screen the 13 indicators composed of evaluation index system for the actual situation of Shaanxi.( see Table 1)

Table1 Low-Carbon Economic Evaluation Indicator System

\begin{tabular}{|c|c|c|c|}
\hline $\begin{array}{l}\text { Target } \\
\text { layer }\end{array}$ & $\begin{array}{c}\text { Criteria layer } \\
\text { (level } \\
\text { indicators) }\end{array}$ & Indicator layer (secondary indicators) & $\begin{array}{l}\text { Indicator } \\
\text { type }\end{array}$ \\
\hline \multirow{13}{*}{$\begin{array}{l}5 \\
0 \\
\sum_{1} \\
1 \\
0 \\
0 \\
0 \\
0 \\
0 \\
0 \\
0 \\
0 \\
0 \\
0 \\
0 \\
0 \\
2 \\
2 \\
0 \\
0 \\
0 \\
0 \\
0 \\
0 \\
2 \\
2 \\
0 \\
0\end{array}$} & \multirow{10}{*}{$\begin{array}{c}\text { Low-carbon } \\
\text { technology } \\
\text { indicators }\end{array}$} & GDP(One hundred million Yuan) $\quad \mathrm{X}_{1}$ & positive \\
\hline & & Per capita GDP rate $(\%) \quad X_{2}$ & positive \\
\hline & & The city living garbage harmless treatment rate (\%) $\mathrm{X}_{3}$ & positive \\
\hline & & $\begin{array}{l}\text { Sewage treatment facilities processing capacity (ten thousand } \\
\text { tons/day) } \quad \mathrm{X}_{4}\end{array}$ & positive \\
\hline & & Industrial solid waste comprehensive utilization rate (\%) $\mathrm{X}_{5}$ & positive \\
\hline & & Industrial $\mathrm{SO}_{2}$ sulfuring quantity(ton) $\quad \mathrm{X}_{6}$ & positive \\
\hline & & Carbon emissions (ten thousand tons) $\quad \mathrm{X}_{7}$ & negative \\
\hline & & $\begin{array}{l}\text { Energy consumption per unit of GDP (tons of standard coal/ten } \\
\text { thousand Yuan) } \mathrm{X}_{8}\end{array}$ & negative \\
\hline & & Energy consumption (ten thousand tons of standard coal) $\quad \mathrm{X}_{9}$ & negative \\
\hline & & Every ten thousand people have public transit vehicle (scale table) $\mathrm{X}_{10}$ & positive \\
\hline & \multirow{3}{*}{$\begin{array}{l}\text { Social } \\
\text { environmental } \\
\text { index indictors }\end{array}$} & The forest coverage rate $\left(\mathrm{m}^{2}\right) \quad \mathrm{X}_{11}$ & positive \\
\hline & & Built up area green coverage rate (\%) $\mathrm{X}_{12}$ & positive \\
\hline & & $\begin{array}{l}\text { Environmental pollution control investment proportion of GDP (\%) } \\
\mathrm{X}_{13}\end{array}$ & positive \\
\hline
\end{tabular}




\section{Comprehensive Evaluation Method of Factor Analysis}

\section{A. The Model of Factor Analysis [8]}

Factor analysis is a statistical method used to describe variability among observed variables in terms of a potentially lower number of unobserved variables called factors. Factor analysis searches for such joint variations in response to unobserved latent variables. The observed variables are models as linear combinations of the potential factors, plus error terms. The information gained about the interdependencies between ob-served variables can be used later to reduce the set of variables in a dataset.

Now supposing $X=\left(X_{i j}\right)_{n \times p}$ is a sample observation matrix composed of $\mathrm{P}$ evaluation indicator variables and $\mathrm{N}$ sample points that

$$
X=\left[\begin{array}{cccc}
x_{11} & x_{12} & \cdots & x_{1 \mathrm{p}} \\
x_{21} & x_{22} & & x_{2 \mathrm{p}} \\
\vdots & & & \vdots \\
x_{\mathrm{n} 1} & x_{\mathrm{n} 2} & \cdots & x_{\mathrm{np}}
\end{array}\right]
$$

Namely $X_{i}=\left(x_{i 1}, x_{i 2} \cdots, x_{i p}\right), x_{i j}$ is a value of sample point in $i_{t h}$ the indicator and $j_{t h}$ sample point. The data matrix $X=\left(X_{i j}\right)_{n \times p}$ till uses form after the non-dimensional process. The factor analysis model in matrix term is Eq.1:

$X=A F+\varepsilon$

$A=\left(a_{i j}\right)_{p \times m}$ is called as factor loading matrix; $f_{1}, f_{2}, \cdots f_{m}(m \leq p)$ is vector of common factors; $\varepsilon_{i}(i=1, \cdots, m)$ is vector of special factors, generally we set hypothesis as follows Eq.2 4:

$\operatorname{COV}(f, \varepsilon)=0$

$D_{\varepsilon}=D(\varepsilon)=\operatorname{diag}\left(\delta^{2}{ }_{1}, \delta^{2}{ }_{2} \cdots, \delta^{2}{ }_{n}\right)$

$D_{f}=D(f)=\mathrm{I}_{\mathrm{m}}$

\section{B. The Procedure of Factor Analysis[9-10]:}

The procedure of comprehensive evaluation using factor analysis

1) Standardizing the original data matrix $x_{n \times p}$ to calculate the covariance matrix of standardized indicators namely the correlation matrix.

2) Calculating the correlation matrix $R$ eigenvalus $\lambda_{1} \geq \lambda_{2} \geq \lambda_{3}$ and corresponding eigenvectors ,then calculate eigenvalues of the contribution rate and cumulative contribution rate.

3) Based on contribution rate eigenvalues and cumulative contribution rate to determine the number of common factors, the establishment factor model.

4) Calculating factor loading matrix.

5) Rotating factor loading matrix and simplifying its structure to making the meaning of common factors is more explicit.

6) Constructing comprehensive evaluation model, and implementing the comprehensive evaluation and analysis. Comprehensive evaluation model Eq.5,

$$
F=\sum w_{i} f_{i}
$$

$f_{i}$ is vector of common factor; $\quad w_{i}=\frac{\lambda_{i}}{\sum_{k=1}^{p} \lambda_{k}}$ is common factor's contribution rate.

\section{The Empirical Analysis of Shaanxi Low-Carbon Economy}

\section{A. Data Collecting and Processing}

The first step is collecting the data in Shaanxi province in recent years. The data is collected and summarized from the China Statistical Yearbook (2003-2011), Shanxi Statistical Yearbook 
(2003-2011) and the Shaanxi Provincial Bureau of Statistics, published by Science and Technology Department of Shaanxi Province, Shaanxi Province National Economic and Social Development Statistics Bulletin (2003-2011), finally formed the original summary data shown in Table2. In order to eliminate the negative influence of dimension indicators and to deal with comprehensive summary question resulting from different dimensions, the non-dimensional process is needed, the authors adopt standard process method based on relative study[8].supposing $X_{i j}$ is a positive evaluation indicator, Then its standard value after standard process is $X_{i j}=\frac{x_{i j}-\overline{x_{i}}}{s_{i}}$,if $X_{i j}$ is a negative indicator, then its standard value is $X_{i j}=\frac{\overline{x_{i}}-x_{i j}}{s_{i}}$

Table2 The Original Data

\begin{tabular}{|c|c|c|c|c|c|c|c|c|c|}
\hline \multirow{2}{*}{ Indicator } & \multicolumn{10}{|c|}{ Original Data } \\
\cline { 2 - 11 } & 2003 & 2004 & 2005 & 2006 & 2007 & 2008 & 2009 & 2010 & 2011 \\
\hline $\mathrm{x}_{1}$ & 2587. & 3175.6 & 3933.7 & 4744 & 5757.2 & 7314.5 & 8169.8 & 10123.4 & 12512.3 \\
\hline $\mathrm{x}_{2}$ & 7028 & 8587 & 10161 & 12138 & 14607 & 18246 & 21688 & 27133 & 33464 \\
\hline $\mathrm{x}_{3}$ & 38.5 & 39.1 & 39.8 & 60.2 & 52.4 & 68.52 & 69.2 & 79.8 & 90.27 \\
\hline $\mathrm{x}_{4}$ & 340.7 & 301.74 & 262 & 306 & 317.22 & 330.79 & 329 & 373.21 & 385.56 \\
\hline $\mathrm{x}_{5}$ & 18.5 & 21.7 & 24 & 38.2 & 41.6 & 40.3 & 53.97 & 54.66 & 60.13 \\
\hline $\mathrm{X}_{6}$ & 91550 & 126000 & 120000 & 18300 & 249000 & 364000 & 745000 & 1076000 & 108000 \\
\hline $\mathrm{X}_{7}$ & 2635. & 3119.6 & 3746.3 & 4106.7 & 4645 & 5047.0 & 5282.7 & 5795.32 & 6172.01 \\
\hline $\mathrm{x}_{8}$ & 1.51 & 1.49 & 1.42 & 1.43 & 1.36 & 1.28 & 1.172 & 1.129 & 1.113 \\
\hline $\mathrm{X}_{9}$ & 3919 & 4692.7 & 5571 & 6129 & 6775 & 7417 & 8044 & 8882 & 9760.77 \\
\hline $\mathrm{x}_{10}$ & 7.4 & 7.9 & 8.2 & 10 & 11 & 12.13 & 13.36 & 12.64 & 15.59 \\
\hline $\mathrm{X}_{11}$ & 28.74 & 32.55 & 32.55 & 37.3 & 37.3 & 37.26 & 37.26 & 37.26 & 37.26 \\
\hline $\mathrm{X}_{12}$ & 26.31 & 29.35 & 30.21 & 36.2 & 37.7 & 38.12 & 38.8 & 38.3 & 38.68 \\
\hline $\mathrm{X}_{13}$ & 0.92 & 1 & 0.99 & 1.1 & 0.79 & 1.1 & 1.5 & 1.79 & 0.61 \\
\hline
\end{tabular}

B. The Application of Factor Analysis in Empirical Analysis

From factor analysis feasibility test, it is known that KMO value suitable for factor analysis. Using factor analysis software SPSS16.0 to get the calculated initial solution which is a general description of the original variables are shown in Table3 Component Initial Eigenvalues columns and Component columns. Wherein the second column is the variance factor (also the eigenvalues), which is a index factor to measure of the degree of importance. The first factor describes the variance of the original 10.642, second factor describes 1.035 . According to the criteria generally the eigenvalues of a extraction factor greater than 1, so here two factors extracted from the original variables describe the total variance 11.677; the third column is the variance of each factor contribution rate, the variance of principal two factors rate is $71.677 \%$ and $18.146 \%$, we can get the cumulative contribution rate of $89.823 \%$ of variance, it can be said that two factors reflect the most information of the original variables, the result is satisfied

Table3 Total Variance Explained

\begin{tabular}{|c|c|c|c|c|c|c|}
\hline \multirow{2}{*}{ Component } & \multicolumn{3}{|c|}{ Initial Eigenvalues } & \multicolumn{3}{c|}{ Rotation Sums of Squared } \\
\cline { 2 - 7 } & Total & \% of & Cumulative & Total & \% of & Cumulative \\
\hline 1 & 10.642 & 81.860 & 81.860 & 9.318 & 71.677 & 71.677 \\
\hline 2 & 1.035 & 7.963 & 89.823 & 2.359 & 18.146 & 89.823 \\
\hline$\ldots$ & $\ldots$ & $\ldots$ & & & & \\
\hline 13 & $-4.550 \mathrm{E}-1$ & $-3.500 \mathrm{E}-15$ & 100.000 & & & \\
\hline
\end{tabular}

From factor loading matrix we can see that the representative variance of each factor isn't outstanding(except individual scalars), which can't reflect the data structure and connection among the factors, this paper adopts The average orthogonal rotation method to calculate the factor loading matrix, the result is shown in Table4. 
Table4 Final Factor Loading Matrix

\begin{tabular}{|l|c|c|}
\hline \multicolumn{1}{|c|}{ Indicator } & \multicolumn{2}{c|}{ Component } \\
\cline { 2 - 3 } & 1 & 2 \\
\hline GDP(One hundred million Yuan) $\mathrm{X}_{1}$ & 0.970 & 0.215 \\
\hline Per capita GDP rate (\%) $\mathrm{X}_{2}$ & 0.972 & 0.195 \\
\hline The city living garbage harmless treatment rate (\%) $\mathrm{X}_{3}$ & 0.935 & 0.294 \\
\hline Sewage treatment facilities processing capacity (ten thousand tons/day) $\mathrm{X}_{4}$ & 0.849 & -0.15 \\
\hline Industrial solid waste comprehensive utilization rate (\%) $\mathrm{X}_{5}$ & 0.890 & 0.425 \\
\hline Industrial SO ${ }_{2} \quad$ sulfuring quantity(ton) $\mathrm{X}_{6}$ & 0.912 & 0.238 \\
\hline Carbon emissions (ten thousand tons) $\mathrm{X}_{7}$ & -0.89 & -0.42 \\
\hline Energy consumption per unit of GDP(tons of standard coal/ten thousand Yuan) & 0.898 & 0.381 \\
\hline Energy consumption (ten thousand tons of standard coal) $\mathrm{X}_{9}$ & -0.91 & -0.37 \\
\hline Every ten thousand people have public transit vehicle (scale table) $\mathrm{X}_{10}$ & 0.940 & 0.282 \\
\hline The forest coverage rate (m ${ }^{2}$ ) $\mathrm{X}_{11}$ & 0.609 & 0.660 \\
\hline Built up area green coverage rate (\%) $\mathrm{X}_{12}$ & 0.605 & 0.718 \\
\hline Environmental pollution control investment proportion of GDP (\%) $\mathrm{X}_{13}$ & 0.006 & 0.763 \\
\hline
\end{tabular}

The evaluation indicators which have relatively high load coefficient in the first factor are: GDP $\left(\mathrm{X}_{1}\right)$, per capita GDP $\left(\mathrm{X}_{2}\right)$, city living garbage harmless treatment rate $\left(\mathrm{X}_{3}\right)$, sewage treatment facilities processing capacity $\left(\mathrm{X}_{4}\right)$, industrial solid waste comprehensive utilization rate $\left(\mathrm{X}_{5}\right)$, industrial SO2 desulphurization capacity $\left(\mathrm{X}_{6}\right)$, carbon emissions volume $\left(\mathrm{X}_{7}\right)$, energy consumption per unit of GDP $\left(\mathrm{X}_{8}\right)$,l energy consumption $\left(\mathrm{X}_{9}\right)$, every ten thousand people have public transit vehicle $\left(\mathrm{X}_{10}\right)$. these indicators reflect the technology development ability of regional economic development and low-carbon capacity from different aspects, namely the first factor mainly reflects the technical and economic indicators of low-carbon.

The evaluation indicators which have relatively high load coefficient in the second factor are: the forest coverage rate $\left(\mathrm{X}_{11}\right)$, built up area green coverage rate $\left(\mathrm{X}_{12}\right)$, environmental pollution control investment proportion of GDP $\left(\mathrm{X}_{13}\right)$. These indicators reflect the social environmental condition from different sides, namely the second factor is focus on low-carbon economy and social environment indicator.

\section{Building the Model}

Factor model variables will be represented as a linear combination of common factors, vice versa; common factors can be expressed as a linear combination of the original variables. According to the regression method of factor score

calculation, the original variables can be expressed as a linear combination of common factors, then calculate the diluted least squares estimation namely factor score coefficients, according to the factor score coefficients and the original value of the variables can calculate the weight of each factor score(see Table5); according to the values of each factor and level of low-carbon economic development factor score constructs evaluation model Eq.6:

$$
F=\left(w_{1} F_{1}+w_{2} F_{2}\right) /\left(w_{1}+w_{2}\right)
$$

$F$ represents the comprehensive score of the level of low-carbon economy development; $W_{i}(i=1,2)$ is the with variance contribution rate; $F_{1}, F_{2}$ is the first and second factor score

Table5 Shaanxi the Level Score of Low-Carbon Economy Development(2003 2011)

\begin{tabular}{|c|c|c|c|c|}
\hline Year & F1 & F2 & F & Rank \\
\hline 2003 & -1.313 & -1.125 & -1.275 & 9 \\
\hline 2004 & -1.327 & -0.130 & -1.085 & 8 \\
\hline
\end{tabular}




\begin{tabular}{|l|c|c|c|c|}
\hline 2005 & -1.320 & 0.305 & -0.992 & 7 \\
\hline 2006 & -0.477 & 0.569 & -0.266 & 6 \\
\hline 2007 & 0.086 & -0.096 & 0.049 & 5 \\
\hline 2008 & 0.387 & 0.210 & 0.351 & 4 \\
\hline 2009 & 0.578 & 0.928 & 0.649 & 3 \\
\hline 2010 & 1.027 & 0.869 & 0.995 & 2 \\
\hline 2011 & 2.360 & -1.530 & 1.574 & 1 \\
\hline
\end{tabular}

\section{Evaluation Result Analysis and Related Suggestions}

\section{A. Evaluation Results}

Overall, the development of low-carbon economy in Shaanxi province has been improving, especially since 2007, a significant increase in speed. In order to further understand those factors promoted awareness and constrained regional low-carbon economic development, authors put forward further analysis combined with the factor analysis conclusions and Table4:

1) Analysis of low-carbon technologies and economic indicators. This factor, on behalf of low-carbon economic development indicators $\mathrm{X}_{1}, \mathrm{X}_{2}$ loads up, shows economic development is crucial for development of low-carbon economy. Recent year indicators of economic development in Shaanxi province are rising constantly thanks to the GDP increases year by year, which is the primary factors of a low-carbon economy development; $\mathrm{X}_{3}, \mathrm{X}_{4}, \mathrm{X}_{5}, \mathrm{X}_{6}, \mathrm{X}_{7}, \mathrm{X}_{8}, \mathrm{X}_{9}, \mathrm{X}_{10}$ indicators mainly reflect low-carbon technologies, and carbon emissions $\left(\mathrm{X}_{7}\right)$ and energy consumption $\left(\mathrm{X}_{9}\right)$ are the main factors that constrain the development of low-carbon economy to enhance the level ,these are relative with Shaanxi's industrial structure, level of economic development, energy consumption structure and other factors, which is the common problems in the process of socio-economic development, and the problems are not only in Shaanxi but also facing the country. With the social development and the adjustment of economic structure, low-carbon technology has played a fundamental role to improve the level of development of low-carbon economy.

2) Analysis of low-carbon social and environmental factors. This factor represents low-carbon economy and society on environmental development indicators $\mathrm{X}_{11}, \mathrm{X}_{12}, \mathrm{X}_{13}$ highest loads. In recent years, Shaanxi province focuses on Shaanxi ecological construction, these three indicators, in particular the level of the first two indicators increased year by year, which has a huge role in enhancing the level of low-carbon economic development, and promoting investment for environmental governance to keep increasing, especially for environmental pollution control investment to GDP $\left(\mathrm{X}_{13}\right)$, which has played a significant role for the province to enhance the level of development of low-carbon economy, however, these also reflect policy is still taking the road after pollution, at the same time, show application in use of low-carbon technology is inadequate, which is key place to improve.

\section{B. Conclusions and Suggestions}

Low-carbon economy as a new form of economic development began in the developed countries to address global climate change and the energy crisis, a new concept of social development and mode. Especially China in recent years for the implementation of the sustainable development strategy, and the establishment of a resource-saving and environment-friendly society goal, the development of low-carbon economy is the fundamental way. Due to fewer domestic low-carbon economy, has not yet formed a low-carbon economy authoritative evaluation system.

This paper is based on the Shaanxi reality, refer to the relevant literature and reference to the existing method to establish Shaanxi low-carbon economy evaluation index system, through the front of the evaluation indicator system of each table weights compare and research data research, this paper argues that it can from the following several aspects to improve Shaanxi low-carbon economic development level:

1) Strengthen the low-carbon technology development and support. The government should continue to strengthen the low-carbon technology and industry investment, change the original treatment after pollution situation to the source management, it mainly comes from low-carbon 
technology application. Shaanxi university education resources rich for the development of low-carbon technology and application has advantaged condition, the government should strengthen the guide do university-industry cooperation.

2) Actively adjust the industrial structure. Shaanxi in the west belongs to the less developed regions, in recent years the economy has made a great progress, but environmental pressure also grows day by day. Especially in recent years, national implementation of low-carbon economic development strategy, which means that high energy consumption, high pollution, high emission industries must to low energy consumption, low pollution, low emission based new industry transformation, in order to reduce greenhouse gas emissions and environmental pollution. Therefore, Shaanxi should actively adjust the industrial structure, develop the low-carbon industry, especially should pay attention to high-tech industries such as biological industry, photovoltaic industry, etc.

3) The development of low-carbon traffic. By the above data can be seen, in recent years Shaanxi private owned cars growth rate was significantly increased the situation, but the development of the public transportation system is not obvious, so develop low-carbon traffic can effectively promote the province low-carbon economic development, therefore, need to promote the new energy, low energy consumption car, control the growth, strengthen the public transportation investment.

4) Advocate low-carbon consciousness. Through a series of publicity activities to improve the awareness of low-carbon, we advocate more than travel by public transportation, using low-carbon products, change the existing pattern of consumption, the real awareness of low-carbon will be root in people's heart and carry out the real action.

\section{Reference}

[1] Jiafeng Fu, Guiyang Zhuang, Qingxian Gao. The concept of low-carbon economy identification and evaluation of construction of the indicator system [J]. China Population Resource and Environment, 2010, (8): 38-43

[2] Dali Hu, Ding Shuai. Low-carbon economy evaluation index system [J]. Science and Technology Progress and Policy, 2010, (22):160-164

[3] Ma Jun, Zhou Lin, Li Wei. City low-carbon economic evaluation indicator system construction[J]. Science and Technology Progress and Policy, 2010, (11):165-167

[4] Yichang Ye, Mingfeng Huang. Low-carbon economy evaluation index system and empirical research[J]. Statistics and Decision, 2011, (8):47-49

[5] Liu Rong, Xu Zheng, Li Yue. Low-carbon economy evaluation index system and empirical research-An example of a county in Hebei Province [J]. Economic Forum, 2010, (5):37-41

[6] Bimei Feng. Hubei Province low-carbon economic evaluation indicator system construction [J]. China Population Resource and Environment, 2011, (3):54-58

[7] Yanfeng Sun. City low-carbon economic comprehensive evaluation method-Xiamen low -carbon economic evaluation indicators system idea [J]. China's National Conditions and Strength, 2011, (3):55-58

[8] Fenhong Li, Xiao Wang. Factor Analysis and Their Application in General Evaluation of Students[J].Journal of Shangluo University, 2008(5)55-58.

[9] Huixuan Gao. Applied Multivariate Statistical Analysis [M]. Beijing: Beijing University Press 2005:293-320

[10] Zhigang Song, Leilei Xie. SPSS16.0 Practical Teaching Materials[M].Beijing: People's Posts and Telecommunications Press, 2008:246-25 